\title{
Raspberry Extract as Both a Stabilizer and a Reducing Agent in Environmentally Friendly Process of Receiving Colloidal Silver
}

\author{
Jolanta Pulit, ${ }^{1}$ Marcin Banach, ${ }^{1}$ Michał Zielina, ${ }^{2}$ Barbara Laskowska, ${ }^{1}$ and Kamil Kurleto ${ }^{1}$ \\ ${ }^{1}$ Cracow University of Technology, Faculty of Chemical Engineering and Technology, Warszawska Street 24, 31-155 Cracow, Poland \\ ${ }^{2}$ Cracow University of Technology, Faculty of Environmental Engineering, Warszawska Street 24, 31-155 Cracow, Poland
}

Correspondence should be addressed to Jolanta Pulit; pulitjolanta@gmail.com

Received 16 June 2013; Accepted 20 August 2013

Academic Editor: Renyun Zhang

Copyright ( $) 2013$ Jolanta Pulit et al. This is an open access article distributed under the Creative Commons Attribution License, which permits unrestricted use, distribution, and reproduction in any medium, provided the original work is properly cited.

\begin{abstract}
An ecofriendly method of nanosilver obtaining has been studied. The process involves the chemical reduction method carried out in aqueous environment. Silver nitrate (V) was applied as a silver ions source. Raspberry extract was used as a natural source of both reducing and stabilizing agents. The total amount of phenolic compounds was determined by the Folin-Ciocalteu method. Obtained nanoparticles were analyzed by the dynamic light scattering technique so as to determine the particles size and suspension stability which was characterized by an electrokinetic potential. The results confirmed that the size of some nanoparticles was under $100 \mathrm{~nm}$.
\end{abstract}

\section{Introduction}

Nanosilver is one of the most thoroughly investigated nanomaterials and owes its popularity to its biocidal properties [1]. Its antimicrobial activity is associated with the characteristic structure of nanoparticles. They are characterized by a high fraction of surface atoms so that nanoparticles have a greater affinity for interactions with thiol groups, after which the destruction of the bacteria follows [2]. Biological activity is therefore a very important factor, so that nanosilver is used where asepsis is highly desirable. Mostly, this applies in biomedical engineering, cosmetology, food packaging industry, textile industry, crops, animal husbandry, and so forth [3]. Due to the fact that nanosilver suspensions are a valuable antimicrobial product, several preparation methods have been developed. Chemical and photochemical reduction, laser ablation, thermal decomposition, electrochemical methods, and microwave irradiation are the most important [4-7]. In order to understand the specificity of the chemical reduction reaction, electron processes accompanying this process must be considered. This occurs by taking electrons from ions, atoms or molecules. This is possible if chemical species which provide a charge during electron oxidation reactions are present in the system $[8,9]$.
Recently, using nanosilver as a biological agent has become increasingly common. Such an idea aims at the synthesis of nanometric silver in accordance with the principles of "green chemistry." Thanks to the use of bacteria or extracts of various parts of plants, it is possible to derive nanoparticles without the employment of well-known synthetic stabilizers and reducing agents [10]. The development of nanosilver preparation processes while respecting "green chemistry" principles was the intention of the authors. It was decided to find a solution that would allow the use of one substance acting as both a stabilizing and a reducing agent. Limiting the amount of raw materials has an influence on the process costs and reduces energy consumption. This assumption was carried out using a plant extract, which largely reflects the ideas of environmental technologies. In order to obtain nanosilver, the literature describes methods of carrying out the reaction in a chemical reduction, using a substance acting as a reductant and a stabilizer. Sodium citrate and gallic acid are such substances [11]. The existing state of knowledge allows us to provide a compound composed of similar atomic connections, characterized by the analogical properties of gallic acid. For example, ellagic acid (2,3,7,8-tetrahydroxychromeno[5,4,3-cde]chromene-5,10-dione) is such a substance. Raspberry fruits are a natural source. Its molecule 
TABLE 1: The ranges of independent variable variation in the dried raspberry fruit extraction process.

\begin{tabular}{lccc}
\hline Extraction method & Dried raspberry fruit weight $[\mathrm{g}]$ & Extraction process duration [min] & Process temperature [ $\left.{ }^{\circ} \mathrm{C}\right]$ \\
\hline Soxhlet apparatus & $0.90-18.00$ & $180-480$ & - \\
Round-bottom flask & $0.30-6.00$ & $5-180$ & $30-70$ \\
Reactor & $0.30-6.00$ & $5-180$ & $90-130$ \\
\hline
\end{tabular}

is a dimer of gallic acid and creates a system of four condensed rings [12]. The use of raspberry extract as a source of ellagic acid offers the possibility of direct silver ion reduction, as it has strong antioxidant effects, similar to many other polyphenols. Furthermore, minor amounts of other compounds with antioxidant properties, such as gallic acid, ascorbic acid, and quercetin that also contribute to efficiently carrying out the chemical reduction, are also present in raspberry extract. The presence of other organic compounds from the group of polyphenols, tannins, and flavonols allows stabilizing emerging suspensions with no need to add other factors that inhibit the growth of metallic silver agglomerates [13].

\section{Materials and Methods}

2.1. Reagents. Silver nitrate (V), $\mathrm{AgNO}_{3}, 99.90-99.99 \%$ pure, was applied as a source of silver ions. Sodium hydroxide $(\mathrm{NaOH})$ was used to adjust the $\mathrm{pH}$. Water extract of the dried raspberry fruits was used as both a reducing and a stabilizing agent of the emerging nanosilver suspension. Disodium phosphate and potassium dihydrogen phosphate (V), in amounts of $0.5938 \mathrm{~g}$ and $0.4539 \mathrm{~g}$, respectively, were used to prepare the phosphate buffer applied in electrochemical analysis. Subsequently, the salts were dissolved in water $\left(50 \mathrm{~cm}^{3}\right)$ and mixed together in a ratio of $1: 4$ to give a buffer at $\mathrm{pH} 6.5 \pm 0.05$.

\subsection{Methods}

2.2.1. Raspberry Fruit Extract Preparation. Acquisition of organic compounds from the dried raspberry fruit was performed by extraction in the aqueous phase. In order to accomplish this, three-stage laboratory equipment was used, including a Soxhlet apparatus, a round-bottom flask with a reflux condenser placed in a water bath, and a magnetic stirrer, in high-pressure laboratory reactor (Parr Instrument A2256HC12EE Heater Assembly), which allows for reaching temperatures higher than $100^{\circ} \mathrm{C}$. High pressure is produced without the addition of any inert gas but just by heating the contents of the stainless vessel to a high temperature. The ranges of input parameter variations which were established in order to carry out the extraction process are shown in Table 1.

Carrying out the extraction in a Soxhlet apparatus set consisted of weighting out a specified quantity of raw material and placing it in a holder in the apparatus attachment. Water $(300 \mathrm{~g})$ was placed in the round-bottom flask as the solvent. The extraction process proceeded for a specified time. In the case where the extraction carried out in a round-bottom flask,
TABLE 2: Variation ranges of independent variables in the process of obtaining nanosilver.

\begin{tabular}{lc}
\hline Parameter & Variation ranges \\
\hline $\mathrm{AgNO}_{3}$ concentration & $0.000483-0.001931 \mathrm{M}$ \\
Polyphenol weight & $4-10 \mathrm{mg} / \mathrm{cm}^{3}$ \\
$\mathrm{pH}$ & $7-11$ \\
Temperature & $5-40^{\circ} \mathrm{C}$ \\
\hline
\end{tabular}

the reactants contained in it (dried raspberries and water) were heated to the desired temperature in a water bath while stirring with a magnetic stirrer for a predetermined time. In order to carry out the extraction in a high-pressure reactor, after weighing the raw material and the extractant, they were placed in a reaction vessel, and after the lid was closed, the temperature was set, and the mixing system was enabled; then the process proceeded for a specified time. After the extraction, the extraction vessel contents were transferred to plastic containers and subsequently filtered. The supernatant was analyzed spectrophotometrically (UV-VIS) in a wavelength range of $\lambda=350-800 \mathrm{~nm}$. Total polyphenol content was determined in the supernatant by the Folin-Ciocalteu method.

2.2.2. Preparation of Nanosilver Suspension. The method consisted of performing the chemical reduction of silver ions from aqueous silver nitrate (V) solution with the compounds contained in the aqueous extract of the raspberry fruits in the presence of sodium hydroxide as a $\mathrm{pH}$ controller. The variation ranges of the input parameters in the nanosilver production processes are shown in Table 2.

The synthesis proceeded as follows: under conditions of continuous stirring at room temperature, $1 \mathrm{~cm}^{3}$ of the extract (at the appropriate polyphenol content) was added to $24 \mathrm{~cm}^{3}$ of an aqueous silver nitrate (V) solution (at the appropriate concentration) in a beaker placed on a magnetic stirrer. In order to achieve the desired $\mathrm{pH}$ of the reaction mixture, an appropriate amount of aqueous sodium hydroxide solution at a concentration of $0.01 \mathrm{M}$ was added. The beaker contents were transferred to a plastic container, which was placed at a predetermined temperature in order to maintain the reduction process under appropriate temperature conditions. The obtained nanometric silver suspensions were analyzed spectrophotometrically to determine the time after which no further change was observed in the absorbance value. This time pointed to a cessation in the process of reduction and completion of the process. Subsequently, the resulting suspensions were examined to determine the average particle 
size and the electrokinetic potential, $\xi$, which was achieved using the dynamic light scattering technique (DLS).

\subsubsection{Research Methods}

(1) Voltamperometric Measurements. In order to confirm the reducing nature of the raspberry fruit extract, electrochemical studies were performed on an electrochemical analyzer (BAS100B/W) coupled to a bioanalytical system, USA computer. Extract analysis was carried out by cyclic voltamperometry $(\mathrm{CV})$, in a three-electrode dish, in a phosphate buffer at a constant $\mathrm{pH}$. Measurements were performed at room temperature in air. The working electrode was made of glassy carbon (GC) with an area of $0.066 \mathrm{~cm}^{2}$. A platinum electrode in the form of a wire was the counter electrode, and an $\mathrm{Ag} / \mathrm{AgCl}$ silver chloride electrode $\left(3 \mathrm{~mol} / \mathrm{dm}^{3} \mathrm{NaCl}\right)$ was the reference electrode.

(2) Total Polyphenol Content Determination by FolinCiocalteu Method. The Folin-Ciocalteu method is the most widely used way of determining the total polyphenol content in different extracts. This method is based on a reversible reaction involving the reduction of molybdenum (VI) contained in the Folin-Ciocalteu reagent to molybdenum (V). The phenolate anion, formed in an alkaline environment, is the reducing agent. The reaction is demonstrated by the color change of the mixture (from colorless to blue), indicating the formation of molybdenum in the $\mathrm{V}$ oxidation state. The resulting reduced form of molybdenum has an absorption maximum at a wavelength $\lambda=745-750 \mathrm{~nm}$, and the peak intensity (absorbance) indicates the content of polyphenols in the extract. The determination of the total content of polyphenolic compounds in aqueous raspberry extracts began with the preparation of the calibration curve for standard solution, using gallic acid. After obtaining the equation of the calibration curve $A=f$ (gallic acid concentration $\left.\left[\mathrm{mg} / \mathrm{cm}^{3}\right]\right)$, spectrophotometric studies were carried out, and the absorbance of each of extract was read. Subsequently, the gallic acid concentration was calculated, and this was used as the background to calculate the total polyphenol content in the samples [14].

(3) Sample Characteristics. In the spectrophotometric analysis, a Rayleigh UV1800 spectrophotometer was used which works at a wavelength range of $\lambda=190-1100 \mathrm{~nm}$ and a bandwidth of $2 \mathrm{~nm}$. In order to determine the average size of nanoparticles, the dynamic light scattering technique was used. Studies were performed using a particle size analyzer (Zetasizer Nano ZS Malvern Instruments Ltd.), with a measurement range from $0.6 \mathrm{~nm}$ to $6.0 \mu \mathrm{m}$. The suspension was centrifuged on the Thermo Scientific Sorvall MX Series Floor Model Micro-Ultracentrifuge. Parameters of centrifugation were as follows: $50000 \mathrm{rpm}, 15 \mathrm{~min}$, and $20^{\circ} \mathrm{C}$. After centrifugation, the morphology of the nanoparticles was illustrated by scanning electron microscopy (SEM-EDS) and the elemental distribution on the obtained solid surface was determined by the sample surface constant mapping. SEM-EDS analyses were performed by X-ray electrodispersive spectrometry
TABLE 3: Potential and current peaks values for the oxidation and reduction wave.

\begin{tabular}{lcccccc}
\hline & \multicolumn{3}{c}{ Oxidation wave } & \multicolumn{3}{c}{ Reduction wave } \\
& $E[\mathrm{mv}]$ & $I_{p, a}[\mu \mathrm{A}]$ & $\Delta I_{p, a}$ & $E[\mathrm{mv}]$ & $I_{p, k}[\mu \mathrm{A}]$ & $\Delta I_{p, k}$ \\
\hline Wave 1 & 277 & 2.44 & - & -690 & -6.65 & - \\
Wave 2 & 276 & 2.49 & 0.05 & -690 & -6.25 & 0.40 \\
Wave 3 & 270 & 2.58 & 0.14 & -690 & -6.04 & 0.61 \\
\hline
\end{tabular}

(Quantax200 Bruker AXS Microanalysis GmbH-with EDS with an XFlash 4010 detector). The detector was coupled to a scanning electron microscope (LEO 1430VP).

\section{Results}

\subsection{Extracts}

3.1.1. Voltammetric Measurement Results. As a result of these studies, a voltammogram showing the oxygen reduction process in the presence of raspberry extract was obtained (Figure 1).

For the anode potential values, a clear oxidation wave was seen with a maximum at about $270 \mathrm{mV}$. Comparing these results and the literature, it was found that the oxidation peak of the extract was related to the content of gallic acid. The oxidation process began at about $90 \mathrm{mV}$. Three measurements showed an increase in the intensity of current peak maximum $\left(I_{p, a}\right)$. The blur of the oxidation wave was also seen. Small values of current difference peaks $\left(\Delta I_{p, a}\right)$ (Table 3 ) and the oxidation wave blur indicate the adsorption of active substances contained in the raspberry extract on the electrode surface and thus the capture of these substances. In the reverse process (in the direction of negative potentials), no reduction wave was observed, which demonstrates the reversibility of the oxidation process. In the values of cathode potential, from about -580 to $-890 \mathrm{mV}$, a clear peak of reduction was observed. Based on the literature data, it was found that this range corresponds to two-electron oxygen molecule reduction which leads to hydrogen peroxide formation $\left(\mathrm{O}_{2}+2 \mathrm{H}^{+}+2 \mathrm{e}^{-} \rightarrow \mathrm{H}_{2} \mathrm{O}_{2}\right)$ [15]. Three measurements showed a decrease in the intensity of current peak maximum $\left(I_{p, k}\right)$ (Table 3). This demonstrates that the reduced oxygen molecules were consumed while the oxidation process was running.

The electrochemical data confirm the reduction properties of compounds contained in the aqueous raspberry extract, so it can be used as a factor for producing $\mathrm{Ag}^{+}$ions in the zero oxidation state. Compounds contained in the extract such as mucilage, and especially pectin, are capable of stabilizing nanosilver suspensions in a very effective way [16].

\subsubsection{Raspberry Fruit Extract Preparation}

Effect of Independent Variables on the Dependent Variables. In the order to carry out the process of preparing an aqueous raspberry extract, a design of experiments (DOE) methodology was used. When using a Soxhlet apparatus, 


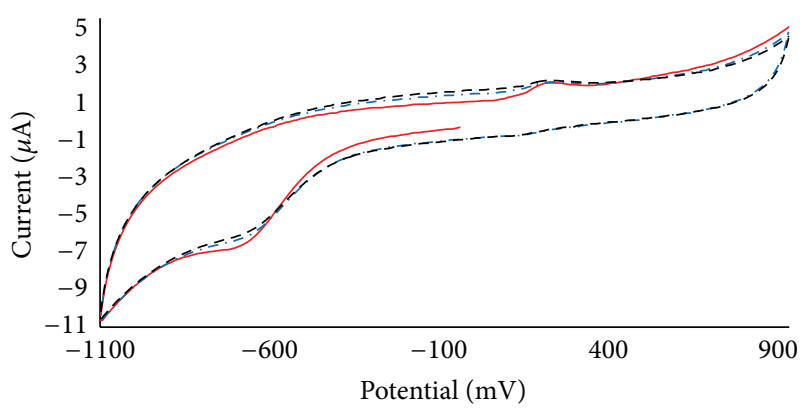

FIGURE 1: A CV curve showing the process of oxygen reduction after adding $0.1 \mathrm{~cm}^{3}$ of an aqueous raspberry extract.

the effect of two independent variables on the dependent variable (the complete plan, $3^{(2-0)}$ ) was adopted. For the processes carried out in a round-bottom flask and in the highpressure reactor, the analysis examined the dependence of the output variables from the three input values (fractional plan, $\left.3^{(3-1)}\right)$. Plan matrices and variable values are provided in Table 4.

Spectrophotometric Analysis. In order to determine the optical properties of the extracts, they were analyzed spectrophotometrically (UV-Vis) in a wavelength range of $\lambda=280$ $800 \mathrm{~nm}$. Figure 2 shows the dependence of the absorbance on the wavelength.

In order to determine which extract is the most effective reductive and stabilizing factor in the synthesis of nanosilver, statistical techniques were used to analyze the data. As a result of the analysis, it was possible to determine the significant impact of independent variables on the dependent variables in the process of obtaining an extract from raspberry fruit. The factors investigated and the results (Table 4) were analyzed by variance analysis and the influence of the input variables on the output variables was evaluated with the statistical significance $\alpha=0.05$. A graphical representation of the standardized effects on the depended variables in the extraction processes conducted by the three different methods is presented in Figure 3.

The graph shows that, when using the Soxhlet apparatus, the degree of extraction depends only on the raspberry fruit dried mass; this was also confirmed by ANOVA, which revealed that the value of the test probability level, $P$, was less than the assumed statistical significance $\alpha=0.05$. The algebraic sign of the standardized effect, which is negative, should be taken under consideration, as it reflects the reduced output variable value with an increase in the input variable value. If the extraction is carried out in a round-bottom flask, the mass of dry fruits and the process temperature have a significant impact on the resulting factor value. The standardized effects chart suggests that the extraction time is a statistically insignificant parameter. In the extraction process carried out in the high-pressure reactor, raspberry fruit dry weight, temperature, and the duration of the process are statistically significant parameters.
3.1.3. Selection of Extract for the Nanosilver Production Process. One of the main goals of extract selection was to find such an extract with a spectrum that did not obscure the spectrum peak originating from the nanosilver suspension, that is, the area in the wavelength range $\lambda=400-500 \mathrm{~nm}$. The extract spectra, in numerical form, were analyzed by a multivariate analysis. For this purpose, the agglomeration method was used as one type of cluster analysis. As a result, all the spectra were divided into three subsets of objects (extract UV-Vis spectra with similar characteristics). The Euclidean distance was used as a measure of the distance between them, and in order to define the similarity between objects, Ward's method was used. According to the adoption of more restrictive criteria isolation clusters (Sneath criterion, equal to 33\%), it was found that the number of clusters of objects was three. Then, the clusters were classified by the $k$-means method, which contributed to assigning the spectra to three clusters so that the elements belonging to a given cluster were most the similar to each other and at the same time, as much as possible, were placed away from objects belonging to other clusters. Figure 4 shows the results of the analysis by the $k$ means method. Based on the cluster analysis, it was found that the percentage of extracted polyphenols in relation to the dry matter in extract used in the synthesis of nanosilver cannot exceed a value of $0.23 \%$ because such an extract contains the maximum amount of polyphenols useful in the synthesis of nanosilver and the UV-Vis spectrum does not obscure the characteristic nanosilver peak.

A prediction of output variables was also made by setting the prediction equation coefficients for the independent variables. They form the basis of the equation, which for the extraction process carried out in a Soxhlet apparatus takes the form of

$$
y_{1 \mathrm{SA}}=0.1310-0.0703 x_{4 \mathrm{SA}}-0.0280 x_{4 \mathrm{SA}}^{2},
$$

where $x_{4 \mathrm{SA}}$ is the raspberry dried fruit weight, $y_{1 \mathrm{SA}}$ is the percentage of extracted polyphenols in relation to the dry matter.

If the extraction was carried out in a round-bottom flask, the mass of dried raspberry fruits and the temperature of the process have a significant impact on the resulting factor. The chart of standardized effects suggests that the extraction time is a statistically insignificant parameter. The predictive equation for the output variable in this method is as follows:

$$
\begin{aligned}
y_{1 \mathrm{RBF}}= & 0.1947+0.0137 x_{5 \mathrm{RBF}}+0.0319 x_{4 \mathrm{RBF}} \\
& +0.0141 x_{4 \mathrm{RBF}}{ }^{2},
\end{aligned}
$$

where $x_{4 \mathrm{RBF}}$ is the raspberry dried fruit weight, $x_{5 \mathrm{RBF}}$ is the process temperature, and $y_{1 \mathrm{RBF}}$ is the percentage of extracted polyphenols in relation to the dry matter.

In the extraction carried out in a high-pressure reactor, the statistically significant parameters are: raspberry dried fruit weight, temperature and the duration of the process. 

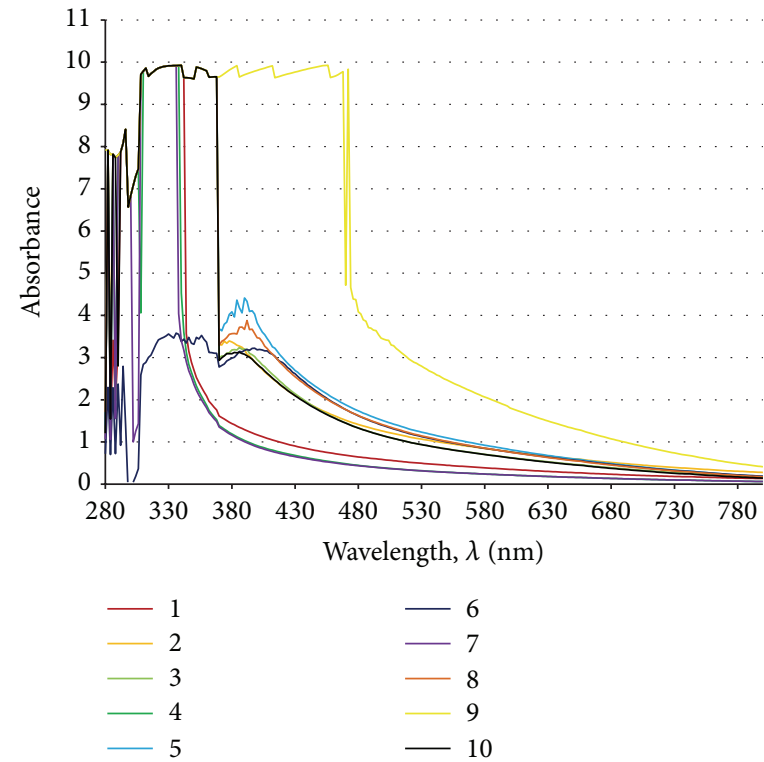
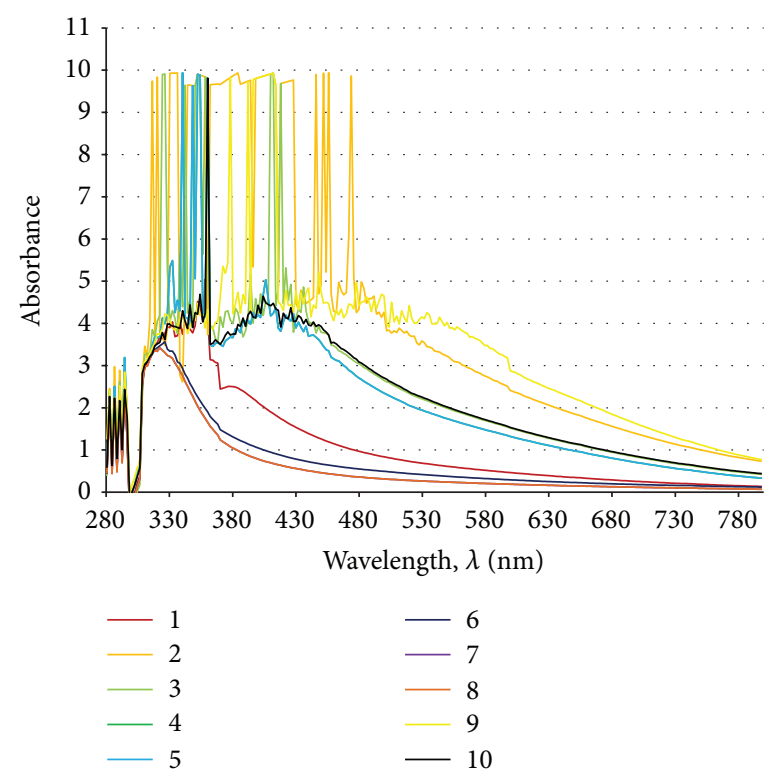

(b)

(a)

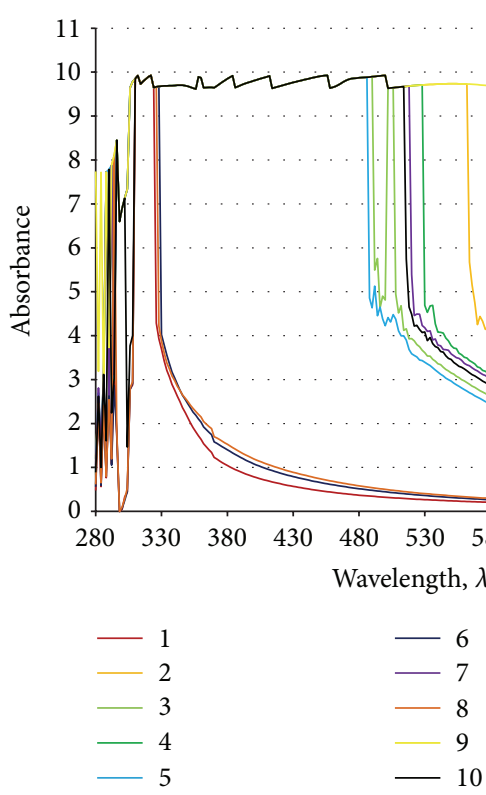

(c)

FIGURE 2: Extracts spectra for (a) Soxhlet apparatus, (b) round-bottom flask, and (c) high-pressure reactor

According to the designated regression coefficients, the predictive equation for the output variable is as follows in (3):

$$
\begin{aligned}
y_{1 \mathrm{HPR}}= & 0.2170+0.0438 x_{5 \mathrm{HPR}}-0.0368 x_{6 \mathrm{HPR}} \\
& -0.0260 x_{6 \mathrm{HPR}}{ }^{2}+0.0271 x_{4 \mathrm{HPR}}{ }^{2},
\end{aligned}
$$

where $x_{5 \mathrm{HPR}}$ is the process temperature, $x_{6 \mathrm{HPR}}$ is the time of process, $x_{4 \mathrm{HPR}}$ is the raspberry dried fruit weight, and $y_{1 \mathrm{HPR}}$ is the percentage of extracted polyphenols in relation to the dry matter.
Approximations of the output variable for different combinations of input values were made. Cluster analysis and approximate profiles allowed us to select the most favorable extraction method, which was also consistent with the principles of green chemistry. Carrying out the extraction process in a round-bottom flask equipped with a reflux condenser was the chosen method. The ideal parameters were $\sim 4.6 \mathrm{~g}$ of raspberry dried fruit weight, and the process should be carried out at a temperature of $30^{\circ} \mathrm{C}$ for $5 \mathrm{~min}$; the ideal percentage of extracted polyphenols in relation to the dry matter is $0.22 \%$ (approximate value: $0.21 \%$ ). 


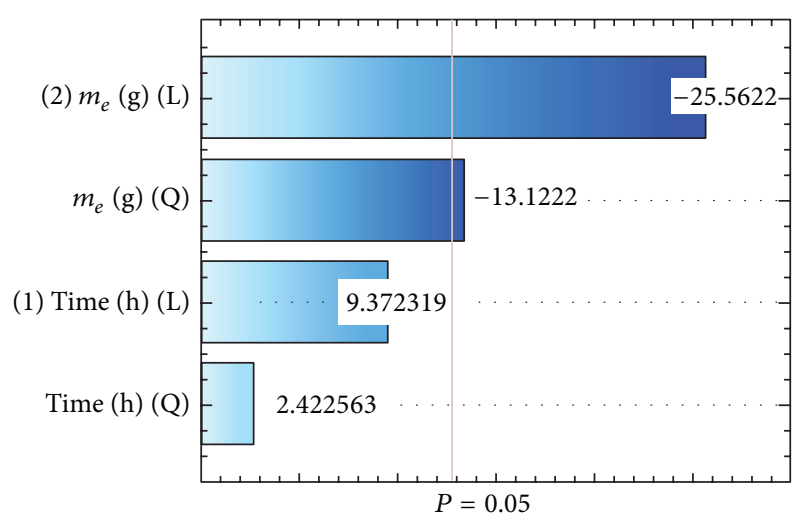

(a)

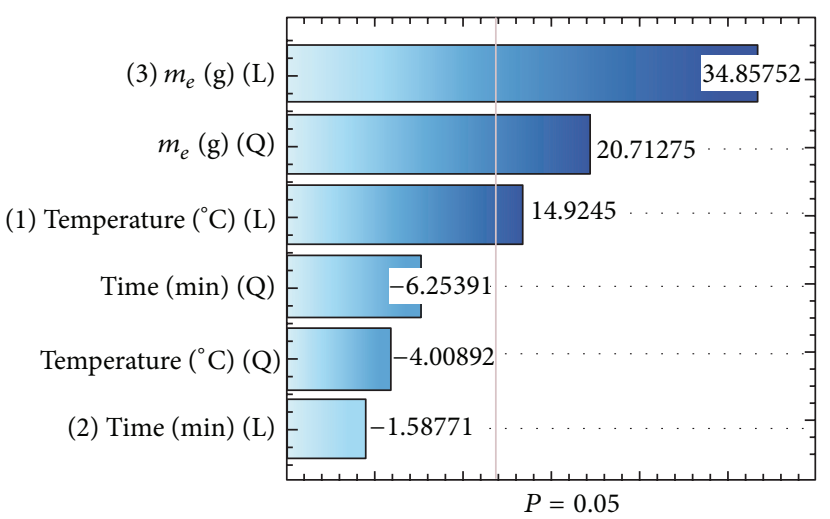

(b)

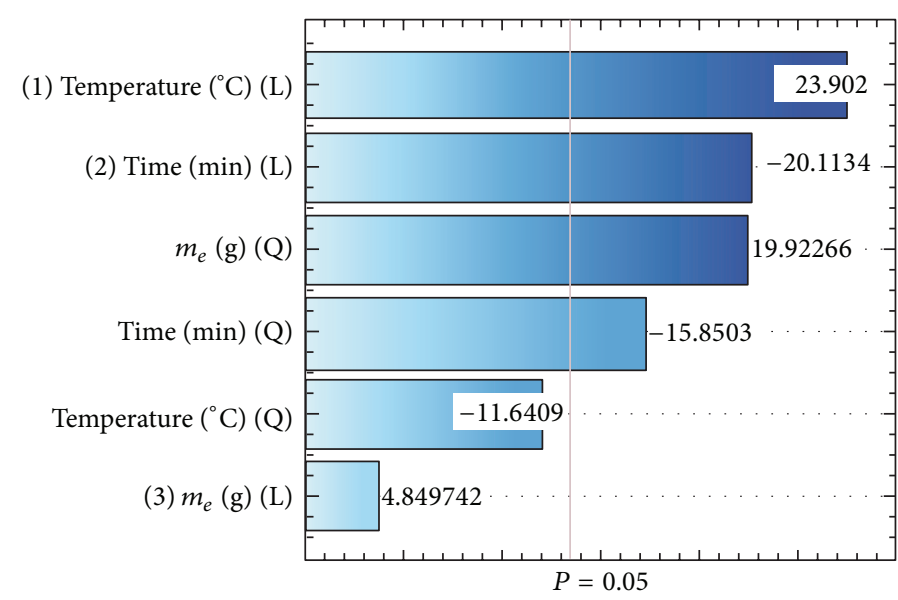

(c)

Figure 3: Pareto chart of standardized effects for the extraction carried out: (a) in a Soxhlet apparatus, (b) in a round-bottom flask, and (c) in a high-pressure reactor.

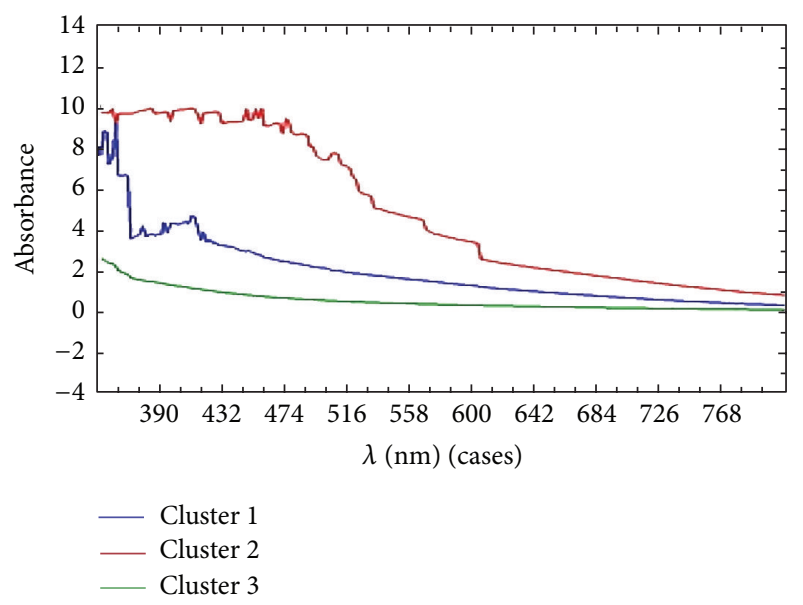

FIGURE 4: Graph of average elements belonging to each cluster.

The extract provided using the optimized parameters was used as a substrate in the process of obtaining nanosilver.

3.2. The Process for Preparing Nanosilver. In the process of nanosilver synthesis, the influence of independent factors
$\left(\mathrm{AgNO}_{3}\right.$ concentration $-x_{7}$, polyphenol weight $-x_{8}, \mathrm{pH}-$ $x_{9}$, and temperature $\left.-x_{10}\right)$ on the average size of nanoparticles $d[\mathrm{~nm}]\left(y_{2}\right)$, electrokinetic potential $\xi[\mathrm{mV}]\left(y_{3}\right)$, and sample stabilization time $t[\mathrm{~h}]\left(y_{4}\right)$ was examined. In order to effectively plan the experiment, the central composition plan was used (Table 5).

The data (Table 5) were analyzed by the analysis of variance (ANOVA) as well as an assessment of the impact of the input variables on the output variables at a statistical significance level of $\alpha=0.05$. The Pareto chart of standardized effects shows a visualization of the results. Assuming a value of statistical significance of 5\%, the analysis permitted us to select the input variables which were statistically significant and had a real impact on the output variables. The set of independent variables which significantly affected the dependent variables are given in Table 6.

Average Size of Nanoparticles. Due to the fact that the distribution of the dependent variable (the average size of nanoparticles) is not normal, its function was transformed by the function $1 / y_{2}$. New variables obtained by this transformation were further analyzed. In the course of the analysis of variance, it was confirmed that $\mathrm{AgNO}_{3}$ concentration, $\mathrm{pH}$, 


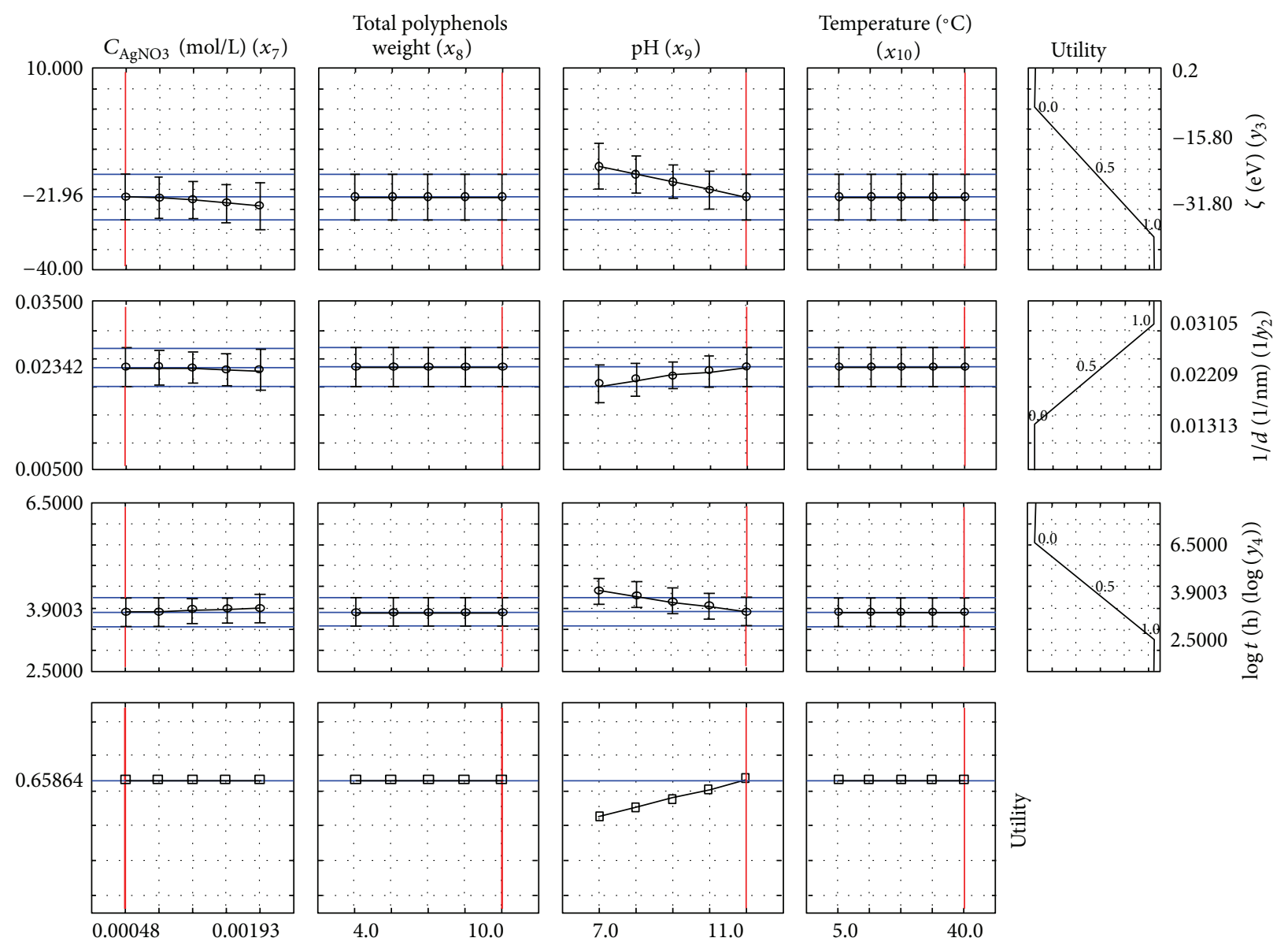

FIGURE 5: Profile of approximated output variables for input variables: $C_{\mathrm{AgNO}_{3}}=0.00048\left[\mathrm{~mol} / \mathrm{dm}^{3}\right]$, total polyphenols weight $=10 \mathrm{mg}$, $\mathrm{pH}=$ 11 , and temperature $=40^{\circ} \mathrm{C}$.

and the temperature of the process were the only factors that significantly affected the value of the average size of the nanoparticles. According to the data (Table 7), it was found that, by increasing the value of the independent variables, the inverse of the average nanosilver particle size $\left(1 / y_{2}\right)$ increased, because the effect sign is positive. This is equivalent to decreasing the average size of nanoparticles, causing an increase in the value of the independent variables which was statistically significant.

A prediction of the dependent variable was also carried out. For this purpose, the regression coefficients for the actual input value were defined. On this basis, the model can be represented in the form of

$$
\begin{gathered}
\frac{1}{y_{2}}=0.0114-150.8805 x_{7}{ }^{2}+0.0008 x_{9}+0.0002 x_{10}, \\
y_{2}=87.7193-0.0066\left(\frac{1}{x_{7}^{2}}\right)+1250\left(\frac{1}{x_{9}}\right)+5000\left(\frac{1}{x_{10}}\right) .
\end{gathered}
$$

Electrokinetic Potential. Analysis of variance allowed us to determine the relationship between the stability of the suspension, which is reflected in the electrokinetic potential and statistically significant input quantities.
The data presented in Table 8 show that an increase in polyphenol weight had a positive influence on the electrokinetic potential. Since the sign of the effect involving the $\mathrm{pH}$ value is negative, an increase causes a reduction of the stability in the final product. The prediction of the output value allowed us to determine the coefficients of the regression equation. On this basis, the model can be represented in the form of an equation as follows in

$$
y_{3}=-10.1667+1.1741 x_{8}-1.9111 x_{9} .
$$

Sample Stabilization Time. Similarly, as in the case of the average particle size, the sample stabilization time distribution was not normal. Therefore, it was converted by a function, which was the natural logarithm of the dependent variable $y_{4}\left(\log \left(y_{4}\right)\right)$. The variables were analyzed further. As a result, the influence of the independent variables on the dependent variables was determined. The results are shown in Table 9.

Based on the algebraic sign of the effects, it was found that increasing the $\mathrm{AgNO}_{3}$ concentration increased the value of the dependent variable due to the positive sign of this effect, while increasing the $\mathrm{pH}$ value caused a decrease in the dependent variable because of the negative sign of this 

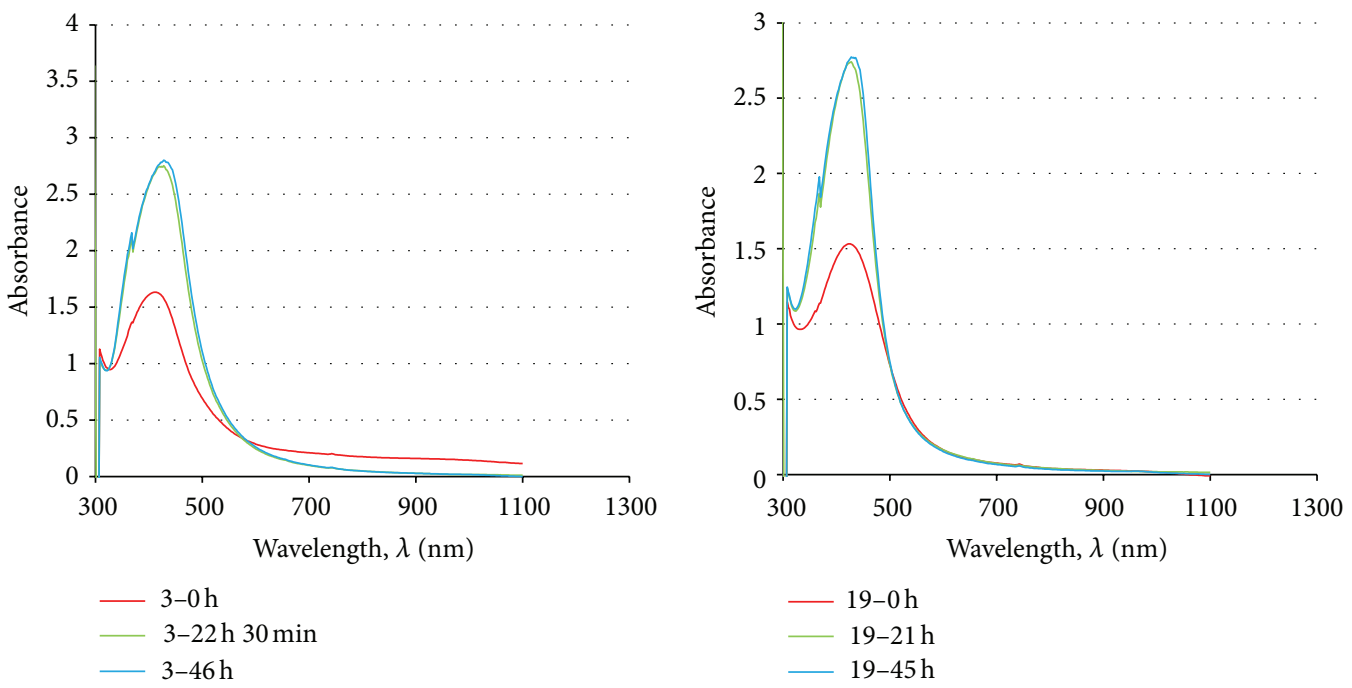

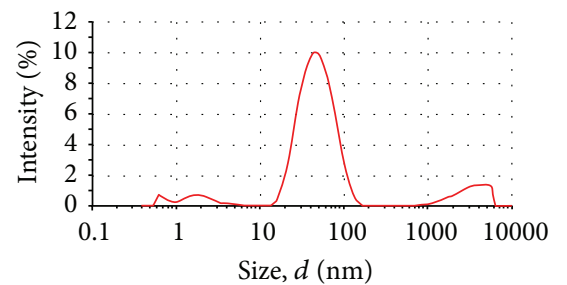

(a)

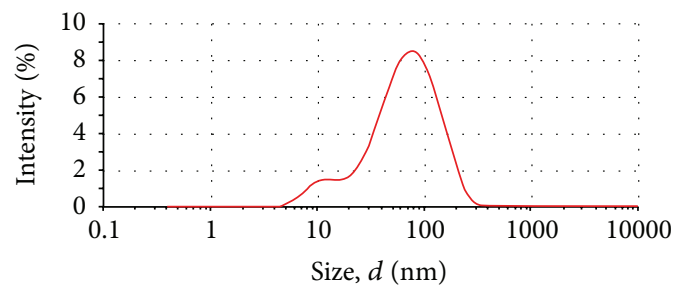

(b)
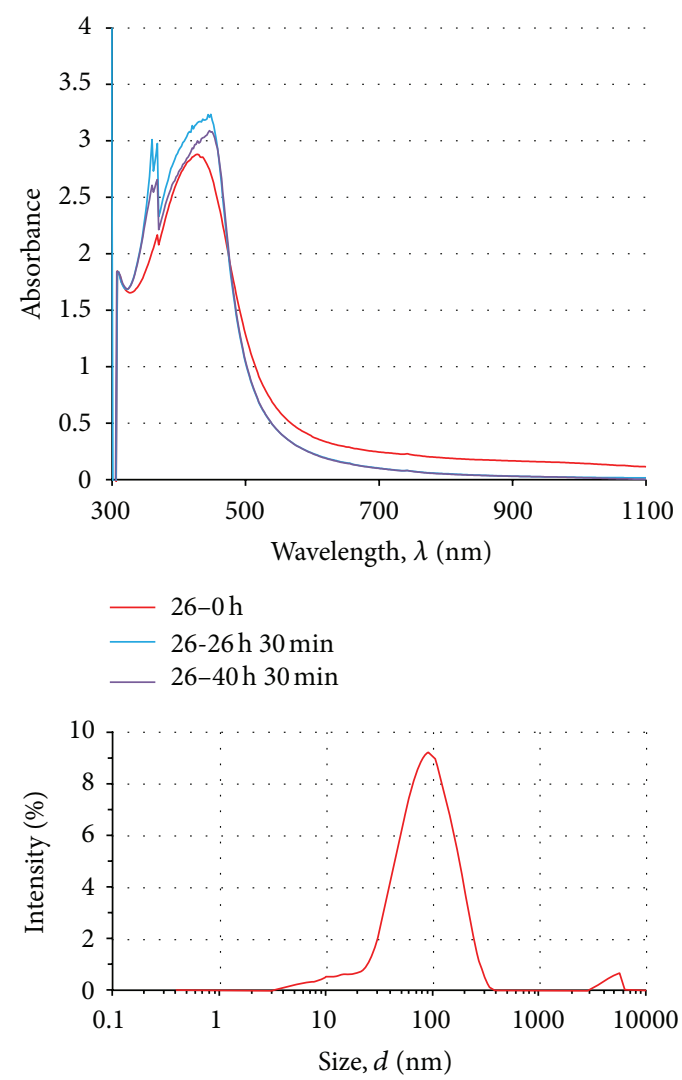

(c)

FIGURE 6: UV-Vis and DLS analysis results of (a) sample 3, (b) sample 19, and (c) sample 26. 
TABLE 4: The plan matrix and the results of measured percentage of polyphenols extracted in relation to the dry matter.

\begin{tabular}{|c|c|c|c|c|}
\hline \multicolumn{5}{|c|}{ Soxhlet apparatus } \\
\hline \multirow{2}{*}{ Number } & \multicolumn{2}{|c|}{ Factors examined } & \multicolumn{2}{|c|}{ Output data } \\
\hline & $\begin{array}{l}\text { Extraction process } \\
\text { duration } x_{1 \mathrm{SA}}[\mathrm{h}]\end{array}$ & $\begin{array}{c}\text { Dried fruit raspberries } \\
\text { weight } x_{2 S A}[\mathrm{~g}]\end{array}$ & \multicolumn{2}{|c|}{ Percentage of extracted polyphenols in relation to the dry matter $y_{1 \mathrm{SA}}[\%]$} \\
\hline 1 & 3.0 & 0.90 & \multicolumn{2}{|c|}{0.07} \\
\hline 2 & 3.0 & 9.45 & \multicolumn{2}{|c|}{0.02} \\
\hline 3 & 3.0 & 18.00 & \multicolumn{2}{|c|}{0.01} \\
\hline 4 & 5.5 & 0.90 & \multicolumn{2}{|c|}{0.08} \\
\hline 5 & 5.5 & 9.45 & \multicolumn{2}{|c|}{0.03} \\
\hline 6 & 5.5 & 18.00 & \multicolumn{2}{|c|}{0.02} \\
\hline 7 & 8.0 & 0.90 & \multicolumn{2}{|c|}{0.07} \\
\hline 8 & 8.0 & 9.45 & \multicolumn{2}{|c|}{0.04} \\
\hline 9 & 8.0 & 18.00 & \multicolumn{2}{|c|}{0.05} \\
\hline 10 & 5.5 & 9.45 & \multicolumn{2}{|c|}{0.03} \\
\hline \multicolumn{5}{|c|}{ Round-bottom flask } \\
\hline \multirow{2}{*}{ Number } & \multicolumn{3}{|c|}{ Factors examined } & Output data \\
\hline & $\begin{array}{c}\text { Extraction process } \\
\text { temperature } x_{1 \mathrm{RBF}}\left[{ }^{\circ} \mathrm{C}\right]\end{array}$ & $\begin{array}{l}\text { Extraction process } \\
\text { duration } x_{2 \mathrm{RBF}}[\mathrm{min}]\end{array}$ & \multicolumn{2}{|c|}{$\begin{array}{cc}\begin{array}{c}\text { Dried fruit raspberries weight } x_{3 \mathrm{RBF}} \\
{[\mathrm{g}]}\end{array} & \begin{array}{c}\text { Percentage of extracted } \\
\text { polyphenols in relation to the dry } \\
\text { matter } y_{1 \mathrm{RBF}}[\%]\end{array}\end{array}$} \\
\hline 1 & 30 & 5.0 & 0.30 & 0.16 \\
\hline 2 & 30 & 92.5 & 6.00 & 0.19 \\
\hline 3 & 30 & 180.0 & 3.15 & 0.20 \\
\hline 4 & 50 & 5.0 & 6.00 & 0.22 \\
\hline 5 & 50 & 92.5 & 3.15 & 0.21 \\
\hline 6 & 50 & 180.0 & 0.30 & 0.14 \\
\hline 7 & 70 & 5.0 & 3.15 & 0.23 \\
\hline 8 & 70 & 92.5 & 0.30 & 0.16 \\
\hline 9 & 70 & 180.0 & 6.00 & 0.25 \\
\hline 10 & 50 & 92.5 & 3.15 & 0.21 \\
\hline \multirow{3}{*}{ Number } & \multicolumn{4}{|c|}{ High-pressure reactor } \\
\hline & \multicolumn{3}{|c|}{ Factors examined } & \multirow{2}{*}{$\begin{array}{c}\text { Output data } \\
\text { Percentage of extracted } \\
\text { polyphenols in relation to the dry } \\
\text { matter } y_{1 \mathrm{HPR}}[\%]\end{array}$} \\
\hline & $\begin{array}{l}\text { Extraction process } \\
\text { temperature } x_{1 \mathrm{HPR}}\left[{ }^{\circ} \mathrm{C}\right]\end{array}$ & $\begin{array}{l}\text { Extraction process } \\
\text { duration } x_{2 \mathrm{HPR}}[\mathrm{min}]\end{array}$ & $\begin{array}{l}\text { Dried fruit raspberries } x_{3 \mathrm{HPR}} \text { weight } \\
\qquad[\mathrm{g}]\end{array}$ & \\
\hline 1 & 90 & 5.0 & 0.30 & 0.20 \\
\hline 2 & 90 & 92.5 & 6.00 & 0.18 \\
\hline 3 & 90 & 180.0 & 3.15 & 0.19 \\
\hline 4 & 110 & 5.0 & 6.00 & 0.22 \\
\hline 5 & 110 & 92.5 & 3.15 & 0.20 \\
\hline 6 & 110 & 180.0 & 0.30 & 0.18 \\
\hline 7 & 130 & 5.0 & 3.15 & 0.40 \\
\hline 8 & 130 & 92.5 & 0.30 & 0.20 \\
\hline 9 & 130 & 180.0 & 6.00 & 0.23 \\
\hline 10 & 110 & 92.5 & 3.15 & 0.19 \\
\hline
\end{tabular}

effect. On this basis, the model can be represented in the form of
In the program Statistica, $\log \left(y_{4}\right)$ corresponds to the natural logarithm of $y_{3}$. Consider that

$$
\log y_{4}=5.3022+25472.7163 x_{7}^{2}-0.1280 x_{9} \text {. }
$$

$$
y_{4}=e^{5.3022+25472.7163 x_{7}{ }^{2}-0.1280 x_{9}} .
$$


TABLE 5: Matrix plan and the values of the output results.

\begin{tabular}{|c|c|c|c|c|c|c|c|}
\hline Number & $\begin{array}{c}C_{\mathrm{AgNO}_{3}} \\
{\left[\mathrm{~mol} / \mathrm{dm}^{3}\right]\left(x_{7}\right)}\end{array}$ & $\begin{array}{c}\text { Total } \\
\text { polyphenols } \\
\text { weight }[\mathrm{mg}]\left(x_{8}\right)\end{array}$ & $\mathrm{pH}\left(x_{9}\right)$ & $\begin{array}{c}\text { Temperature } \\
{\left[{ }^{\circ} \mathrm{C}\right]\left(x_{10}\right)}\end{array}$ & $\begin{array}{c}d[\mathrm{~nm}] \\
\left(y_{2}\right)\end{array}$ & $\zeta[\mathrm{eV}]\left(y_{3}\right)$ & $t[\mathrm{~h}]\left(y_{4}\right)$ \\
\hline 1 & 0.000483 & 4 & 7 & 5 & 59.87 & -20.0 & 117.0 \\
\hline 2 & 0.000483 & 4 & 7 & 40 & 44.06 & -20.0 & 115.0 \\
\hline 3 & 0.000483 & 4 & 11 & 5 & 42.57 & -30.5 & 46.00 \\
\hline 4 & 0.000483 & 4 & 11 & 40 & 35.19 & -27.0 & 93.00 \\
\hline 5 & 0.000483 & 10 & 7 & 5 & 47.06 & -12.9 & 91.00 \\
\hline 6 & 0.000483 & 10 & 7 & 40 & 36.60 & -16.2 & 253.5 \\
\hline 7 & 0.000483 & 10 & 11 & 5 & 47.39 & -24.7 & 45.50 \\
\hline 8 & 0.000483 & 10 & 11 & 40 & 34.71 & 0.1 & 44.00 \\
\hline 9 & 0.001931 & 4 & 7 & 5 & 52.56 & -16.1 & 117.0 \\
\hline 10 & 0.001931 & 4 & 7 & 40 & 44.54 & -17.1 & 116.0 \\
\hline 11 & 0.001931 & 4 & 11 & 5 & 59.15 & -31.8 & 96.00 \\
\hline 12 & 0.001931 & 4 & 11 & 40 & 37.61 & -31.8 & 68.00 \\
\hline 13 & 0.001931 & 10 & 7 & 5 & 44.03 & -14.3 & 62.50 \\
\hline 14 & 0.001931 & 10 & 7 & 40 & 43.77 & -17.6 & 72.00 \\
\hline 15 & 0.001931 & 10 & 11 & 5 & 43.38 & -27.7 & 72.50 \\
\hline 16 & 0.001931 & 10 & 11 & 40 & 32.21 & -17.9 & 70.00 \\
\hline 17 & 0.000483 & 7 & 9 & 22.5 & 38.89 & -24.2 & 74.00 \\
\hline 18 & 0.001931 & 7 & 9 & 22.5 & 56.54 & -16.4 & 72.00 \\
\hline 19 & 0.001210 & 4 & 9 & 22.5 & 47.81 & -17.9 & 45.00 \\
\hline 20 & 0.001210 & 10 & 9 & 22.5 & 52.14 & -16.9 & 47.00 \\
\hline 21 & 0.001210 & 7 & 7 & 22.5 & 54.80 & -13.4 & 72.00 \\
\hline 22 & 0.001210 & 7 & 11 & 22.5 & 46.60 & -25.8 & 48.00 \\
\hline 23 & 0.001210 & 7 & 9 & 5 & 76.18 & -20.4 & 47.00 \\
\hline 24 & 0.001210 & 7 & 9 & 40 & 55.85 & 0.2 & 43.00 \\
\hline 25 & 0.001210 & 7 & 9 & 22.5 & 43.74 & -18.6 & 48.00 \\
\hline 26 & 0.001210 & 7 & 9 & 22.5 & 67.21 & -21.8 & 30.50 \\
\hline 27 & 0.001210 & 7 & 9 & 22.5 & 54.90 & -17.0 & 26.00 \\
\hline
\end{tabular}

TABLE 6: Summary of independent and dependent variables.

\begin{tabular}{|c|c|}
\hline Dependent variables & Independent variables \\
\hline Average size of nanoparticles & $\begin{array}{c}\mathrm{AgNO}_{3} \text { concentration, } \mathrm{pH} \text {, and } \\
\text { temperature }\end{array}$ \\
\hline Electrokinetic potential & Polyphenol weight and pH \\
\hline Sample stabilization time & $\mathrm{AgNO}_{3}$ concentration and $\mathrm{pH}$ \\
\hline
\end{tabular}

Based on the approximation profiles (Figure 5), the utility function and green chemistry principles, the parameters used in the nanosilver production process were optimized.

The most favorable process parameters were as follows:

(i) $\mathrm{AgNO}_{3}$ concentration: $0.000483 \mathrm{~mol} / \mathrm{dm}^{3}$,

(ii) weight of polyphenols contained in the raspberry extract: $4 \mathrm{mg} / \mathrm{cm}^{3}$,

(iii) $\mathrm{pH}$ : 9,

(iv) temperature: $22^{\circ} \mathrm{C}$.
TABLE 7: Experimental effects.

\begin{tabular}{lcccc}
\hline & Effect & $\begin{array}{c}\text { Standard } \\
\text { error }\end{array}$ & $t(24)$ & $P$ \\
\hline Constant & 0.0185 & 0.0009 & 19.5778 & 0.0000 \\
$\mathrm{AgNO}_{3}$ concentration & 0.0094 & 0.0023 & 4.0368 & 0.0005 \\
{$\left[\mathrm{~mol} / \mathrm{dm}^{3}\right](\mathrm{Q})$} & & & & \\
$\begin{array}{l}\text { Polyphenols weight }\left[\mathrm{mg} / \mathrm{cm}^{3}\right] \\
(\mathrm{L})\end{array}$ & 0.0031 & 0.0013 & 2.2922 & 0.0314 \\
$\mathrm{pH}(\mathrm{L})$ & 0.0056 & 0.0013 & 4.2096 & 0.0003 \\
\hline
\end{tabular}

$\mathrm{L}$ : linear component of Q: square component.

Figures $6(\mathrm{a})-6(\mathrm{c})$ present results of UV-Vis and DLS analyses of some samples.

\section{Discussion of Results}

This study developed an innovative method for the preparation of nanosilver, in which the key factors affecting the quality of the product were found to be the $\mathrm{AgNO}_{3}$ 
TABLE 8: Experimental effects.

\begin{tabular}{lrccc}
\hline & Effect & $\begin{array}{c}\text { Standard } \\
\text { error }\end{array}$ & $t(24)$ & $P$ \\
\hline Constant & -19.1481 & 1.2889 & -14.8557 & 0.0000 \\
Polyphenol weight $\left[\mathrm{mg} / \mathrm{cm}^{3}\right]$ & 7.0444 & 3.1573 & 2.2312 & 0.0353 \\
(L) & & & & \\
$\mathrm{pH}(\mathrm{L})$ & -7.6444 & 3.1573 & -2.4212 & 0.0234 \\
\hline
\end{tabular}

$\mathrm{L}$ : linear component of Q: square component.

TABLE 9: Experimental effects.

\begin{tabular}{lcccc}
\hline & Effect & $\begin{array}{c}\text { Standard } \\
\text { error }\end{array}$ & $t(24)$ & $P$ \\
\hline Constant & 3.7737 & 0.1091 & 34.5754 & 0.0000 \\
$\mathrm{AgNO}_{3}$ concentration & 1.2683 & 0.2673 & 4.7441 & 0.0001 \\
{$\left[\mathrm{~mol} / \mathrm{dm}^{3}\right](\mathrm{Q})$} & -0.5119 & 0.1543 & -3.3167 & 0.0029 \\
$\mathrm{pH}(\mathrm{L})$ & & & \\
\hline
\end{tabular}

$\mathrm{L}$ : linear component of Q: square component.

concentration, the weight of polyphenols contained in the raspberry extract, the $\mathrm{pH}$ value, and the process temperature. Based on the data, it was found that, by increasing process temperature, the average particles size decreases, which leads to an increase in the reaction kinetics, resulting in a greater number of smaller nanoparticles of a monodispersed nature. Increasing silver nitrate $(\mathrm{V})$ concentration contributes to a reduction in the average nanosilver size. This is related to the formation of a large number of small nanoparticles and a longer suspension stability time. Increasing the amount of the raspberry extract (whose compounds have been shown to have both reducing and stabilizing properties) relative to the $\mathrm{AgNO}_{3}$ concentration prevents the agglomeration of nanoparticles due to electrostatic integrations, such that they have greater stability. The degree of suspension stability is dependent on the $\mathrm{pH}$ value: intensification of alkaline $\mathrm{pH}$ promotes product stability. The higher the $\mathrm{pH}$, the greater the number of smaller nanoparticles produced, since in the case of low $\mathrm{pH}$, the aggregation of existing nanoparticles is favored rather than the nucleation of new ones. This is due to the fact that alkaline conditions stimulate the transformation of the reducing agent in a form which favors charge transfer.

\section{Summary}

As a result of this study, stable suspensions of nanosilver using aqueous raspberry extract were obtained. Statistical analysis techniques were used such that the planning and interpretation of the results were carried out more effectively.

\section{Supporting Information Available}

This information is available free of charge via the Internet at http://pubs.acs.org/.

\section{Acknowledgment}

This work is a part of the project Synthesis and Application of Innovative Nanomaterials with Antimicrobial Properties supported by National Centre for Research and Development under the Project LIDER/03/146/L-3/11/NCBR/2012 for the period of 2012-2015.

\section{References}

[1] R. Vaidyanathan, K. Kalishwaralal, S. Gopalram, and S. Gurunathan, "Nanosilver-the burgeoning therapeutic molecule and its green synthesis," Biotechnology Advances, vol. 27, no. 6, pp. 924-937, 2009.

[2] B. Sadeghi, M. Jamali, S. Kia, A. Amininia, and S. Ghafari, "Synthesis and characterization of silver nanoparticles for antibacterial activity," International Journal of Nano Dimension, vol. 1, p. 119, 2010.

[3] J. Pulit, M. Banach, and Z. Kowalski, "Nanosilver-making difficult decisions," Ecological Chemistry and Engineering, vol. 18, no. 2, pp. 185-196, 2011.

[4] Z. Khan, S. A. Al-Thabaiti, A. Y. Obaid, and A. O. Al-Youbi, "Preparation and characterization of silver nanoparticles by chemical reduction method," Colloids and Surfaces B, vol. 82, no. 2, pp. 513-517, 2011.

[5] M. Nishioka, M. Miyakawa, H. Kataoka, H. Koda, K. Sato, and T. M. Suzuki, "Continuous synthesis of monodispersed silver nanoparticles using a homogeneous heating microwave reactor system," Nanoscale, vol. 3, no. 6, pp. 2621-2626, 2011.

[6] S. Keki, J. Torok, G. Deak, L. Daroczi, and M. Zsuga, "Silver nanoparticles by PAMAM-assisted photochemical reduction of Ag(+)," Journal of colloid and interface science, vol. 229, no. 2, pp. 550-553, 2009.

[7] K. Mallick, M. J. Wihtcomb, and M. S. Scurrell, "Polymer stabilized silver nanoparticles: a photochemical synthesis route," Journal of Materials Science, vol. 39, no. 14, pp. 4459-4463, 2004.

[8] A. Bielański, Chemia Ogólna, Wydawnictwo Naukowe PWN, Warszawa, Poland, 2005.

[9] J. Pulit, M. Banach, L. Tymczyna, and A. ChmielowiecKorzeniowska, "Stan badan i kierunki zmian w otrzymywaniu nanostrukturalnego srebra," Przemysł Chemiczny, vol. 91, p. 1000, 2012.

[10] M. Popescu, A. Velea, and A. Lorinczi, "Biogenic production of nanoparticles," Digest Journal of Nanomaterials and Biostructures, vol. 5, no. 4, pp. 1035-1040, 2010.

[11] Y.-P. Huang, S.-K. Xu, W.-X. Wang, and J.-P. Yuan, "Nano-silver: preparation by gallic acid reduction and reaction mechanism," Chinese Journal of Inorganic Chemistry, vol. 23, no. 10, pp. 16831688, 2007.

[12] D. A. Vattem and K. Shetty, "Biological functionality of ellagic acid: a review," Journal of Food Biochemistry, vol. 29, no. 3, pp. 234-266, 2005.

[13] S. H. Hakkinen, S. O. Karenlampi, H. M. Mykkanen, I. M. Heinonen, and A. R. Torronen, "Ellagic acid content in berries: influence of domestic processing and storage," European Food Research and Technology, vol. 212, no. 1, pp. 75-80, 2000.

[14] H. Strzelecka, J. Kaminska, J. Kowalski, and E. Walewska, Chemiczne Metody Badan Roslinnych Surowcow Leczniczych-Podrecznik Dla Studentow Farmacji, Panstwowy Zaklad Wydawnictw Lekarskich, Warszawa, Poland, 1982. 
[15] A. Cournet, M. Bergé, C. Roques, A. Bergel, and M.-L. Délia, "Electrochemical reduction of oxygen catalyzed by Pseudomonas aeruginosa," Electrochimica Acta, vol. 55, no. 17, pp. 4902-4908, 2010.

[16] S. Pornsak, Chemistry of Pectin and Its Pharmaceutical Uses: A Review, Silpakorn University International Journal, 2003. 

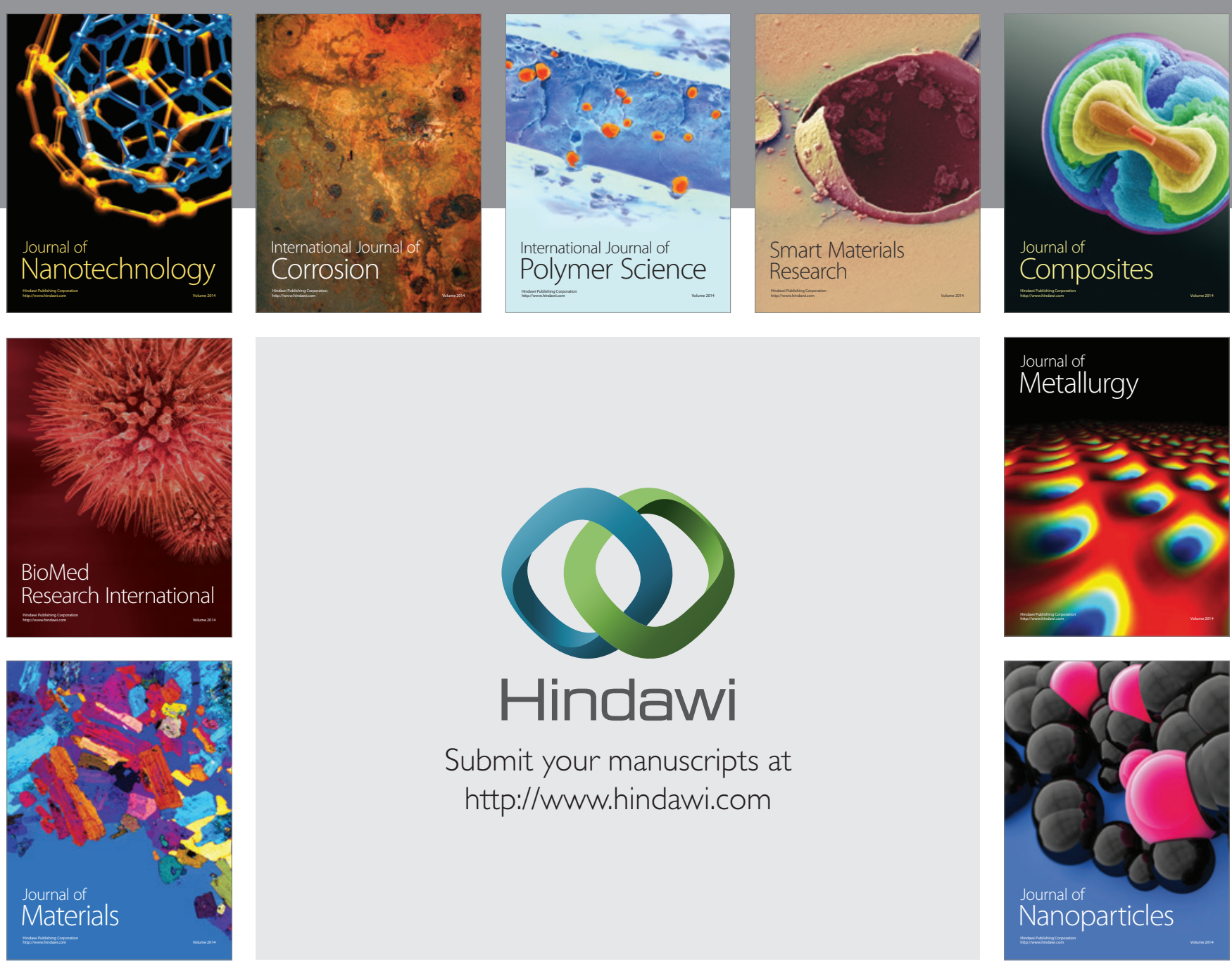

Submit your manuscripts at http://www.hindawi.com
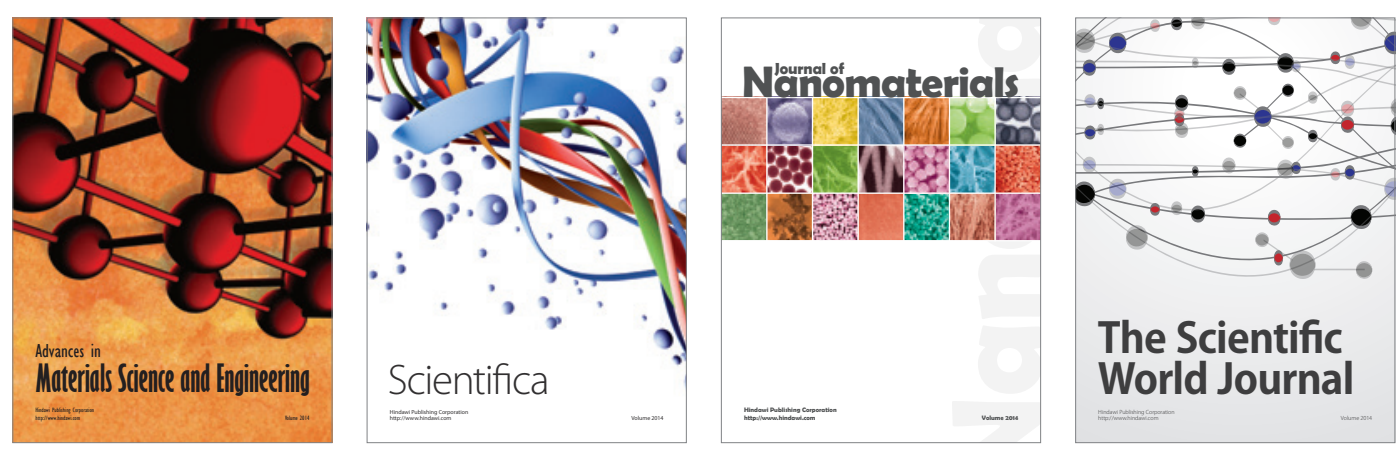

\section{The Scientific World Journal}
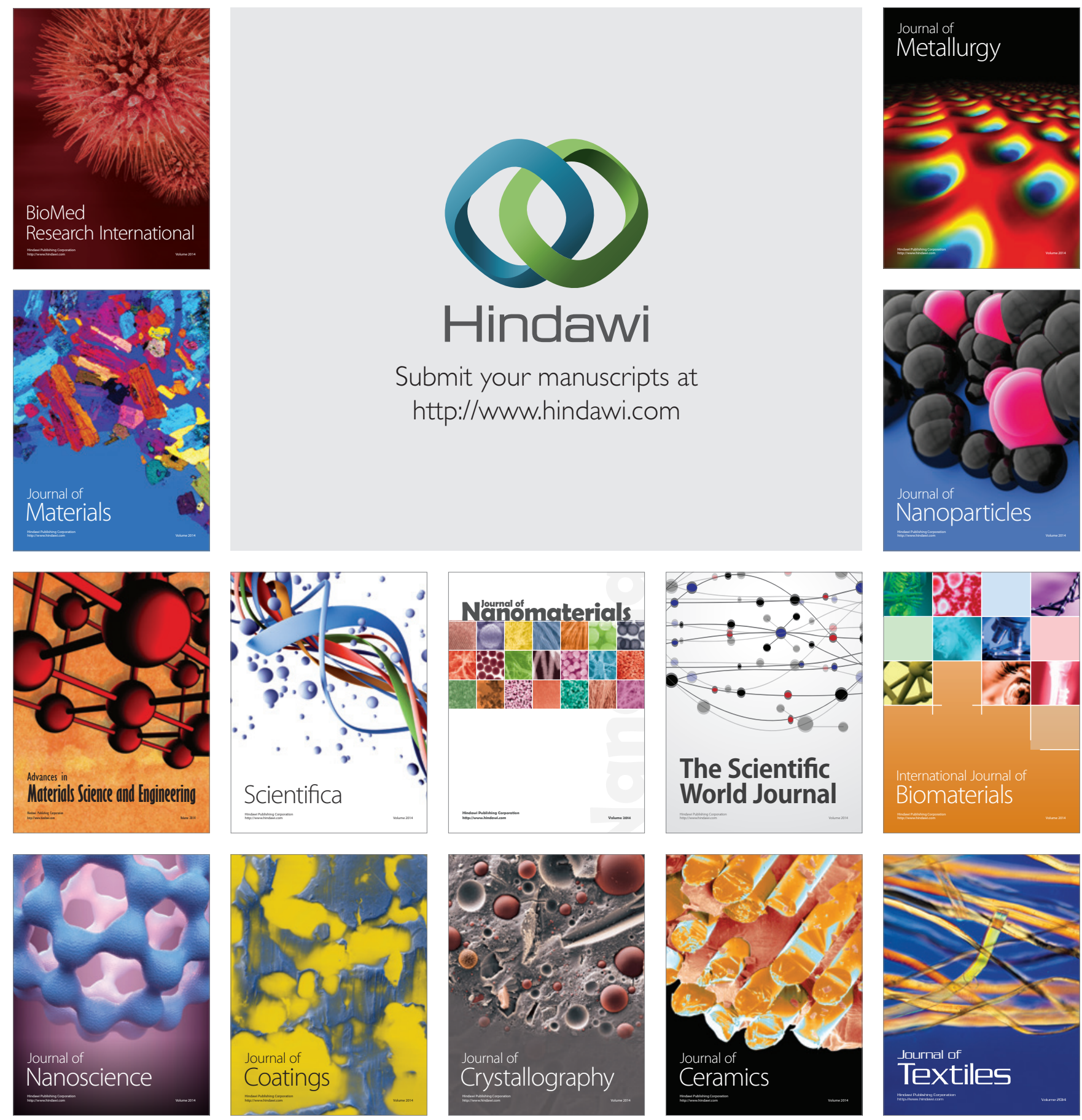